\title{
Notas sobre la casa de los obispos de Córdoba en la Edad Media
}

\author{
Iluminado Sanz Sancho \\ Universidad Autónoma de Madrid
}

\begin{abstract}
RESUMEN
El estudio de la Casa y Corte de los Reyes ha supuesto una serie de novedades y avances importantes en la historiografía europea y española, que se

ha aplicado también a algunos estados nobiliarios. Pero, hasta el momento, esta

problemática y su estudio no se han proyectado sobre los altos eclesiásticos y menos aún en los tiempos medievales. El

presente articulo, reconociendo la dificultad que conlleva la carencia de fuentes suficientes, pretende, no obstante, plantear la posibilidad de este tipo de esiudios en la Historia de la Iglesia y un procedimiento oportuno para su tratamiento. Igualmente, presentar algunos datos y noticias concretas, pertenecientes a la Iglesia de Córdoba, que pueden avalar el interés de este estudio y aventurar un mejor conocimiento de la Historia en la Edad Media.
\end{abstract}

\section{PALABRAS CLAVE}

Historia de la Iglesia. Sociedad medieval. Iglesia de Córdoba. Casa de eclesiásticos.

\begin{abstract}
The study of the Royal House and Court has meant a series of important newness and advances in the European and Spanish historiography, and has also been applied to some noble estates. Although, so far, the study of this subject has not been projected over the upper Ecclesiastics and even less during the Middle Ages. The present article, admitting the difficulty of not having enough sources, attempts, nonetheless, to introduce the possibility of this type of studies in the history of the Church and an appropriate method for its study. It also tries to show some specific data and news belonging to the Church of Córdoba, all of it may guarantee the interest of this study and foretaste a better knowledge of the History during the Middle Ages.
\end{abstract}

\section{KEY WORDS}

History of the Church, Middle Ages Society, Church of Córdoba, House of the Ecclesiastics. 
Examinando la documentación pertinente para nuestros estudios sobre la Iglesia de Córdoba en el medievo, nos llamó la atención que apareciera el término "casa", como un complejo orgánico-funcional y puesto en relación con los eclesiásticos de mayor dignidad socio-económica, no tanto por la cantidad de veces en las que aparece el vocablo, que eran pocas, cuanto por lo significativo del hecho ${ }^{1}$. El término y su relación con los eclesiásticos nos evocó un cierto paralelismo entre los dignatarios de la Iglesia y los nobles laicos, cuyas casas fueron sucesivamente incrementando su importancia y desarrollando ciertas imitaciones con la Casa y Corte de los reyes.

Nuestra curiosidad por conocer algo más sobre el tema de la casa de los eclesiásticos se encontró con la falta de estudios sobre este asunto. Por lo cual recurrimos a temas y ámbitos afines y a períodos próximos, encontrando una historiografía bastante bien desarrollada para la Edad Moderna en lo tocante a las Cortes de los reyes españoles de la Casa de Austria, que ejerce una influencia positiva, aunque más en el ámbito de la historia de las instituciones, en los medievalistas ${ }^{2}$.

El tema de las casas nobiliarias y la tratadística sobre las mismas está menos desarrollado en la historiografía española de la Edad Moderna, pero la producción es representativa de la apertura de los historiadores a las corrientes historiográficas europeas actuales. Por desgracia, la temática todavía está poco e insuficientemente representada en los estudios nobiliarios de la Edad Media ${ }^{3}$.

Ahora bien, no contamos con estudios sobre la casa de los eclesiásticos en el medievo y sólo con muy escasos trabajos en la modernidad ${ }^{4}$. Por lo que nuestra

1 M. C. Quintanilla Raso, "La nobleza", en J. M. Nieto Soria (dir.), Origenes de la Monarquía Hispánica: propaganda y legitimación (ca. 1400-1520), Madrid, 1999, pp. 62-104. “En la Baja Edad Media cuaja una institución de ese eficaz complejo orgánico-funcional, la "Casa»: la organización por el noble del siglo Xv de una nutrida y especializada corte - en la que, por cierto, se intentaba la reproducción de la estructura monárquica-, de un amplio staff, y de un organismo cada vez más rápidamente estructurado y organizado, la "Casa", p. 93.

2 Para la Edad Moderna, baste con aludir a las siguientes obras y a la bibliografía en ellas contenida: J. Martinez Millán y S. Fernández Conti (dirs.), La Monarquía de Felipe II: la Casa del Rey. 2 vols., Madrid, 2005. J. Martínez Millán (dir.), La corte de Carlos V, Madrid, 2000, 2 vols. Para la producción medieval sobre estas materias, puede verse M. Á. LADERO QUESADA, «Historia institucional y política de la Península Ibérica en la Edad Media (La investigación en la década de los 90)", en En la España Medieval, 23 (2000), pp. 441-481, especialmente pp. 451-452 y 464-466 y M. C. Quintanilla Raso, “El protagonismo nobiliario en la Castilla bajomedieval. Una revisión histórica (1984-1997)", en Medievalismo, 7 (1997), pp. 187-234. Como historia institucional, puede consultarse J. DE SALAZAR y Acha, La casa del Rey de Castilla y León en la Edad Media, Madrid, 2000. Una reciente aproximación a la temática cortesana en la monarquia de los Reyes Católicos en Á. Fernandez de Córdova MIRALLES, "Sociedad cortesana y entorno regio", en Medievalismo, 13-14 (2004), pp. 49-78, con amplia bibliografía.

3 Hay algunos trabajos notables, como los de J. M. CALDERón OrTEGA, "La hacienda de los Duques de Alba en el siglo xv: ingresos y gastos", en Espacio, tiempo y forma, Serie Iil, Historia Medieval, t. 9 (1996), pp. 137-227. Etc. y los de I. BECEIRo PITA, El Condado de Benavente en el siglo xV, Madrid, 1998. Particularmente el capítulo 4: La Casa de Benavente, pp. 235-264. Etc.

4 Tenemos noticia de sólo dos articulos, ya antiguos, sobre la casa de dos altos eclesiásticos. J. DoMINGUEZ BORDONA, "Instrucción de fray Hernando de Talavera para el régimen interior de su palacio", en BRAH, 96 (1930), pp. 785-835. A. DE LA TORRE, “Servidores de Cisneros", en Hispania, 6 (1946), pp. 179241. No por casualidad, pensamos, poseemos escritos intormativos de la casa de dos altos eclesiásticos que fueron frailes, porque lo mismo acontece en nuestro caso de los obispos de Córdoba, donde la mejor información consta en el testamento del obispo Fray Gonzalo de lllescas, como se verá. 
labor en este artículo es de lo más humilde: sugerir la importancia del estudio de una temática nueva en la Historia de la Iglesia al hilo del comentario de unos cuantos datos referidos a la Iglesia de Córdoba.

Así la casa de los obispos y de los eclesiásticos en general en el medievo y en la modernidad constituirá un tercer «tipo" de casa, distinto de la casa de los reyes y de la casa de los nobles en varios aspectos, que, sin embargo, no pueden pasar por esenciales hasta el punto de negar la existencia misma de la casa de los eclesiásticos, mientras los textos, los documentos y las mentalidades de aquellos siglos la tuvieron presente.

\section{SOBRE EL PARALELISMO ENTRE LA CASA DE LOS OBISPOS $Y$ LA CASA DE LOS NOBLES LAICOS}

\subsection{Los inicios}

El paralelismo que cabe establecer es mayor o menor, pero constante a lo largo de la historia del episcopado y desde el primer momento en el que aparece el término y el concepto de casa familiar aplicados al obispo, que consta en el enun-

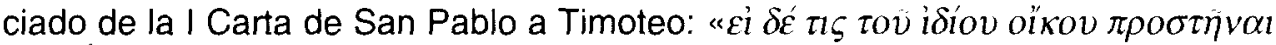

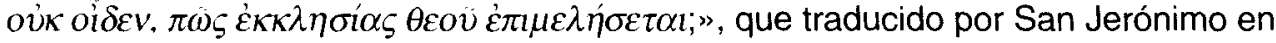
la Vulgata resulta: "Si quis autem domui suae praesse nescit, quomodo ecclesiae Dei, diligentiam habebit?". Es decir: "Pues si alguno no es capaz de gobernar su propia casa, ¿cómo podrá cuidar de la Iglesia de Dios? $>5$.

Veamos el contexto. El apóstol San Pablo, principalmente en I Timoteo, 3, 2-7 (de donde hemos tomado el texto transcrito) y Tito, 2, 6-9 y el apóstol San Pedro en I Pedro 5, 1-4 trazan las virtudes requeridas para las funciones pastorales 0 , como se diría hoy, el retrato robot del obispo. Sus indicaciones, incluida la referencia paulina a la casa episcopal, pasarán a formar parte de los requisitos que aparecen en el Derecho Canónico antiguo y hasta prácticamente en el actual.

En consecuencia, el contexto histórico de la casa episcopal paulina se remite necesariamente a las formulaciones teóricas de Aristóteles y Jenofonte, principalmente, y a los usos que sobre la "oikos" o "casa grande" se practicaban dentro del derecho privado en la cultura greco-romana del siglo 1.

El pensamiento de Aristóteles consta en tres de sus obras clásicas y bien conocidas: Política, Económica y Ética a Nicómaco ${ }^{6}$. En el libro I de la Política, buscando el origen del Estado, el filósofo analiza la familia como comunidad natural

${ }^{5}$ J. M. BOVEr, Novi Testamenti Biblia Graeca et Latina, critico apparatu aucta edidit, $4 .^{\mathrm{a}}$ ed. Madrid, 1959 , p. 618.

${ }_{6}^{6}$ En este breve resumen histórico sobre la tratadistica de la casa nos hemos servido especialmente de la obrita de D. Frigo, "I Padre di Famiglia. Governo della casa e governo civile nella tradizione dell' "economica" tra cinque e seicento, Bulzoni Editore, 1985. 
que precede y da origen al Estado y como etapa intermedia e incompleta de la realización de la vida política. Además, presenta las modalidades del ejercicio del poder en la casa y en la ciudad, habla de la riqueza y de su buen uso, separando claramente el ámbito de la "economía de la casa" del ámbito del comercio y de las actividades externas y da unas indicaciones sobre los esclavos y su utilización en la actividad doméstica. En el libro III de la Económica, Aristóteles se detiene, además, en establecer las cualidades de una buena mujer y en el comportamiento que el hombre ha de tener con ella. En la Ética a Nicómaco da unas normas sobre la "virtud", el uso de las riquezas y hace consideraciones sobre las relaciones de autoridad dentro de la casa.

Jenofonte, en su Económico, aún se centra más en la vida interna de la casa y desarrolla principios fundamentales para una recta organización doméstica y normas sobre el comportamiento de los componentes de la familia.

En consecuencia, con las aportaciones de otros autores griegos antiguos, se había producido un conjunto de saberes, un arte o ciencia sobre la casa del hombre libre y noble y el gobierno de la misma o "económica", que pervivió en medio de la tratadística romana de agricultura y en los resúmenes isidorianos (Etimologias, Sentencias), hasta que fue en gran medida redescubierta en los siglos XII y XIII?

Junto con todo esto, el texto escriturístico de San Pablo incorporó, mediante la traducción jurídico-institucional de San Jerónimo en la Biblia Vulgata, el cúmulo de normas en el Derecho Romano imperial sobre la familia (domus) y el Paterfamilias, cuyas imágenes pervivirán como modélicas en las sociedades romanizadas de los reinos germánicos y épocas posteriores.

A esto hay que añadir la aportación sobre el gobierno episcopal y el gobierno en general que realizó el papa Gregorio Magno en sus escritos, principalmente en la Regula pastoralis, con cuyo libro en las manos se ordenaban los obispos, según aconsejaba Hincmar de Reims. Aqui el gobernante no es el superior, el praesides o el praepositus, sino el rector, y el gobierno no consiste en praesse, sino en prodesse a la comunidad, adquiriendo una mayor carga de paternalismo en la dirección de los asuntos e insistiendo en el ejercicio del poder como misión de servicio para con quienes le están sometidos y en la humildad, que es su condición indispensable ${ }^{8}$.

7 Ya resulta clásico aludir al artículo de O. BRUNNER, "La "Casa grande" y la "oeconómica" de la vieja Europa", en Nuevos caminos de la historia social y constitucional, Buenos Aires, 1976, pp. 87-123, donde se muestra la importancia de la "oeconómica" (literalmente casa grande) en todos los órdenes, incluido el económico, en el Antiguo Régimen europeo.

${ }^{8}$ Las ideas de Gregorio el Grande sobre el ejercicio de la autoridad habían sido anticipadas en la concepción del abad, que era la de San Benito. Como el «rector» de Gregorio, el abad debía saber cómo ser útil (prodesse), más que “imponerse" (praesse) a quienes le estaban sometidos. Esta concepción "paternalista" de la autoridad tenía sus raíces profundas en una larga tradición de pensamiento griego y cristiano. Véase al respecto el apartado de R. A. MARKUS, "Gregory the Great: towards new forms of community», dentro del apartado mayor "The Latin fathers", en J. H. BuRNs (dir.), The Cambridge History of Medieval Political Thought c. 350-c. 1450, Cambridge University Press, 1991, pp. 116-122. 


\subsection{La tratadística medieval}

El renacimiento medieval del siglo XII redescubre la "económica". Así Hugo de San Víctor y sobre todo, Domingo Gundisalvo, el arcediano de Segovia y gran traductor toledano, para quien la "económica" trata de "ordenar la casa y toda la familia. Con ésta se conoce cómo el hombre debe vivir con la mujer, con los hijos, con los siervos y con todos sus domésticos. Y esta ciencia se llama ordenamiento familiar". Por su parte, en el siglo XIII el primer obispo de Cartagena, Pedro Gallego, tradujo del árabe un breve escrito de origen aristotélico sobre el gobierno de la casa en cinco capítulos, que tratan respectivamente sobre la finalidad de la «económica», la relación entre el marido y la mujer, la relación entre padres e hijos, la relación entre patronos y servidores y la adquisición y el uso de los bienes materiales, temas ahora esbozados, pero que serán una constante en la tratadística hasta el siglo $\mathrm{xVIII}{ }^{9}$. En cualquier caso, ya era conocida la obra de Aristóteles y se continuaba profundizando en la misma.

El medievo continuó su reflexión sobre el gobierno de la casa especialmente a través de los Espejos de Príncipes, sobre todo a partir del primero que abordó estas cuestiones, el De regimine principum de Egidio Romano, dividiendo su obra en tres partes: el gobierno de sí mismo, el gobierno de la familia y el gobierno civil ${ }^{10}$. Otros desarrollos aparecerán en el Renacimiento, con tratados ya más elaborados y destinados claramente a las familias nobles.

\subsection{La realidad práctica de la casa: el Derecho Canónico y Las Partidas}

El paralelismo entre la casa episcopal y la de los nobles antiguos y medievales resulta un tanto evidente y siempre dentro de la concepción jurídica romana del Paterfamilias, que no tenia por qué ser un hombre casado y con hijos carnales o adoptivos, sino que podia componer su familia de familiares, clientes, criados y siervos.

En consecuencia, el Derecho Canónico seguía prestando atención a la experiencia administrativa y de gobierno del clérigo idóneo para el episcopado, la cual podía adquirirse dirigiendo un monasterio, una iglesia colegial o una casa propia, así como ayudando a un obispo en las tareas administrativas y pastorales, para lo cual se requeria también una preparación intelectual. A esto hay que añadir los demás requisitos para el episcopado.

Clara demostración de esta situación práctica es el tratamiento y la glosa que dan las Siete Partidas a los requisitos para ser obispo en la Partida I, Título V, le-

${ }^{9}$ D. Frigo, II Padre di Famiglia, op. cit. p. 20 y notas 20 y 25.

10 Véase B. Palacios Martin, «El mundo de las ideas políticas en los tratados doctrinales españoles: los "espejos de príncipes" (1250-1350)", en Europa en los umbrales de la crisis (1250-1350), XXI Semana de Estudios Medievales de Estella, Pamplona, 1995, pp. 463-483. 
yes XXX-LVI, según la edición de la Real Academia de la Historia. No obstante, transcribimos a continuación el texto de la Partida I, según la edición de Arias Bonet, por las razones que damos en nota.

"Ley XXXII Q Quántas cosas deuen auer en sí sennaladamientre los que an de seer esleydos pora obispos. Sant Paulo el apóstol fizo regla de ordenamiento, en que mostró qué costumbres e qué maneras deuen auer los que han de seer electos pora obispos e ordenados pora clérigos ca touo que pues que escogidos auien de seer pora la suerte de Dios, tales auíe mester que fuessen en bondat, que meioría ouiessen sobre todos los otros omnes. E aquella regla que él fizo manda que sea sin pecado mortal e no aya ningún embargo por razón de casamiento, e que sea mesurado en comer e en beuer, e sabidor, e casto, e apuesto, e hospedador que es caridat e almosna, e demostrador de la ley, e non baraiador ni feridor ni cobdicioso, e que sepa bien ordenar su casa" ${ }^{11}$.

Lo cual resulta lógico con el establecimiento en una ley algo posterior sobre los saberes del obispo, donde se dice: "De las cosas que debe ser sabidor el perlado. Sabio et entendido debe ser el perlado, et señaladamiente en estas tres cosas: la primera en la fe... Et la tercera cosa de que los perlados deben ser sabidores es de las cosas temporales para saber bien gobernar los sus obispados et mantener sus casas" ${ }^{12}$.

\section{LA CASA DE LOS OBISPOS CORDOBESES.}

\subsection{La casa de los candidatos a obispos: las personas y los canónigos de la catedral}

La mayor parte de los obispos de Córdoba fueron elegidos de entre los componentes de su propio cabildo catedralicio, particularmente de entre los que poseían una dignidad u oficio. De un total de 25 obispos de Córdoba de 1236 a 1498

" J. A. Arias Bonet (ed.), Primera Partida (Manuscrito Add. 20.787 del British Museum), Universidad de Valladolid, 1975, pp. 86-87. Para esta cita concreta hemos preferido la edición de esta Partida I, sobre el manuscrito del British Museum, porque nos parece más acertada y fiel a la tradición conceptual y manuscrita de la época, particularmente en la oración final del párrafo: «e que sepa bien ordenar su casa”. La edición de la Real Academia de la Historia, en la Ley XXX, que es la correspondiente, prefiere la expresión "et que sepa bien ordenar su eglesia", aun reconociendo que la lección es «casa» en manuscritos tan importantes como los Silense, Toledano 1.2, Escurialense 3 y Biblioteca Real 2.3. A nuestro juicio, la preferencia de "eglesia» por "casa» está claramente equivocada y responde más a convicciones ideológico-religiosas del siglo $\mathrm{x} \mid \mathrm{x}$ que no a una aplicación correcta de las reglas de la crítica, que prefieren la lección más “dificil», que en este caso sería "casa". Además, revela la falta de un estudio más profundo de las ideas y realidades eclesiásticas medievales, más fundadas en la Patrística y aún en el Nuevo Testamento de lo que a primera vista pudiera parecer. Finalmente, está en contradicción con el texto de la ley XXXVII: «... Et la tercera cosa de que los perlados deben ser sabidores es de las cosas temporales para saber bien gobernar los sus obispados et mantener sus casas".

12 Las Siete Partidas del Rey don Alfonso el Sabio, edic. de la Real Academia de la Historia, 3 vols., Madrid, 1807 Vol. I, Partida I, Título V, Ley XXXXVII, pp. 221-222. 
sólo dos no fueron capitulares, porque fueron monje y fraile respectivamente, siendo el resto miembros en su mayoría del cabildo catedralicio de Córdoba y el resto de otros cabildos catedralicios ${ }^{13}$. Por esto parece lógico que hablemos en primer lugar de la casa del grupo de clérigos que, en principio, tenía las máximas posibilidades de formar parte del episcopado.

2.1.1. El edificio de la casa.-Hemos definido la casa de los reyes, nobles, obispos, etc., como "complejo orgánico funcional», del que forman parte, lógicamente, los edificios y construcciones donde se alojan los componentes de la familia, que pueden ser varios y ubicarse en poblaciones distintas. En nuestro caso, los edificios fueron, efectivamente, varios, pero generalmente se denominaron "casas principales" o "casas de morada" aquellos que alojaron a la familia en la ciudad de Córdoba y que solían formar una unidad de elementos de habitación próximos o unidos en una superficie urbana.

Estas casas eran lo suficientemente amplias y estaban bien dotadas de espacios diversos para contener todo lo necesario para la vida de una familia amplia, compuesta por varios familiares, criados y servidores, que podían estar, a su vez, casados y vivir con sus mujeres e hijos. Además, podian complementarse con otras construcciones aledañas o próximas.

El maestrescuela don Lope Gutiérrez de los Ríos fundó por su testamento de 1441 el hospital de Santa María de los Huérfanos, para hombres y mujeres pobres, en sus casas mayores de la collación de $\mathrm{S}$. Pedro de Córdoba, a las que une unas tiendas linderas y las casas también linderas de Alvar Fernández Tejedor, Ruy López y Juan Ruiz de Cañete ${ }^{14}$. El deán don Gil Pérez acabó por acomodar una amplia casa de morada cerca de la cárcel del concejo de Córdoba, en la collación de Santa María, después de comprar y añadir al núcleo central una serie de adquisiciones menores, que dejó en usufructo a su sobrina doña Sol Fernández, por su testamento de 19 de febrero de 1341, junto con otros bienes, como dotación de oficios pro anima en la catedral cordobesa, todo lo cual pasó a ser propiedad del cabildo catedralicio cuando en 1369 doña Sol realizó el acuerdo pertinente ${ }^{15}$.

Las autoridades tenían bien presente la existencia de estas casas de la élite clerical, donde algunas veces encontraban cobijo los malhechores, según ciertas denuncias. Así en 1263, "querelló Ferrand Yénneguez que si algún ome firíe e mataríe a otro, que los de la eglesia amparaban en sus casas e quel non podían haber para complir y justicia". También en 1427 los jurados de Córdoba denunciaron que ciertos malhechores asaltaron a unos presos, que llevaba la justicia de la ciudad por la calle y, después de liberarlos por la fuerza, hiriendo al guardián, se re-

13 Este tema y otros relacionados con los obispos de Córdoba en la E. Media pueden verse en I. SANZ SANCHO, "Episcopologio medieval cordobés. Siglos XIII-XIV» y "Los obispos jel siglo XV», en Hispania Sacra, LIV (2002), pp. 23-67 y pp. 605-677.

14 Testamento de Córdoba, 21 de junio de 1441. Copia de 1533. Archivo del Cabildo de la Catedral de Córdoba (en adelante A.C.C.), caj. L, n, 241.

15 A.C.C., caj. N, n. 237 y caj. V, $n 573$. 
fugiaron en la casa del deán Fernando Pérez de Contreras ${ }^{16}$. Y es que las casas de los miembros del cabildo catedralicio, así como las de los clérigos de la Universidad de Clérigos Beneficiados de Córdoba, tenían varios privilegios: que no podía entrar la justicia seglar en ellas, que no estaban obligadas a aposentar a los huéspedes acompañantes del rey, etc.

2.1.2. Las "casas de estatuto".-Podríamos poner más ejemplos de casas de miembros del cabildo catedralicio, pero bastará con que nos refiramos a la existencia de las denominadas "casas de estatuto", que acabaron por ser un buen número de casas de morada de los miembros del cabildo catedralicio que, sin pertenecer a su patrimonio particular o de linaje, componían una morada adecuada a su categoria social y que eran propiedad del mismo cabildo catedralicio, rigiéndose por ciertas disposiciones o estatutos capitulares en su arrendamiento exclusivo a los miembros del cabildo (de donde proviene su nombre) y que podian exigir una renta anual elevada, de 800 a $1.200 \mathrm{mrs}$. de "moneda vieja" en los siglos XIV y XV ${ }^{17}$.

2.1.3. Los miembros de las casas de los clérigos.-Los componentes de las casas de los clérigos fueron los mismos que los de las casas de los nobles laicos, pues también hubo clérigos casados que mantuvieron su mujer y sus hijos legítimos, así como otros clérigos que tuvieron hijos naturales, los cuales solían vivir en domicilios distintos, generalmente con sus madres.

Los capitulares que mantuvieron mujer e hijos legítimos solian ser racioneros y medios racioneros, si bien también los hubo canónigos e incluso algunos con la dignidad de prior. La razón es que sólo eran tonsurados y permanecian en ese estado clerical inicial, pudiendo ser casados, ya que no recibian ninguna «orden sacerdotal mayor" ni aspiraban a un oficio que exigiera ser ordenado in sacris para su desempeño. No obstante, también se dieron casos de viudos, que accedieron a órdenes mayores.

Podemos poner varios ejemplos de familias de clérigos capitulares con mujer e hijos legítimos, en cuyos testamentos suelen aparecer un hijo o un nieto como heredero de los bienes principales de la familia y la enumeración de la mujer y de los hijos, nietos y sobrinos vivos. Además, también suelen aparecer los criados como objeto de ciertas mandas. Entre los testamentos de los capitulares cordobeses que conocemos proponemos algunos ejemplos, como el del racionero Domingo Gon-

16 Sevilla, 1 de abril de 1263. A.C.C., caj. P, n. 51. F. MAzo Romero, "Tensiones sociales en el municipio cordobés en la primera mitad del siglo XV", en Actas / Congreso de Historia de Andalucia. Andalucia Medieval. II, Córdoba, 1980, II, p. 91.

17 Ignoramos cuándo comienzan a existir dichas "casas de estatuto ", si bien para un estatuto capitular de 1390 ya eran conocidas como tales y posteriormente se sigue reglamentando este asunto. Todavía existían en el siglo xvi, recogiéndose en los Estatutos del obispo Fray Bernardo de Fresneda la enumeración y ubicación de las mismas, unas 20 en total, sitas en la collación de la catedral. B. FresNEDA, Estatutos de la Sancta Yglesia Cathedral de Córdoba, Antequera, 1577, p. 81.

Por lo demás, también los estatutos capitulares ordenaban el plazo durante el cual los servidores del capitular difunto debian dejar libre la casa que ocupaban, que en 1390 elevaron a treinta días, para poder arrendar esa casa a otro capitular que la deseara. 17 de enero de 1390. Biblioteca del Cabildo Catedralicio de Córdoba (en adelante B.C.C.) Ms. 166, f. 50. 
zález ${ }^{18}$, el del compañero Juan Domínguez de Medina ${ }^{19}$ y el del compañero Pedro Pérez de Valdecañas ${ }^{20}$.

Los testamentos de los canónigos y dignidades catedralicias, que suelen ser ordenados in sacris al menos a partir de cierta edad, no acostumbran a contener mandas a los hijos ilegítimos, que eventualmente hubieran podido tener, sino que éstos suelen ser objeto de beneficios económicos en otro tipo de documentos. En sus testamentos abundan las alusiones a sobrinos, hermanos y demás familiares del linaje al que pertenecieran, por lo que nos fijamos solamente en las alusiones a criados y siervos que aparecen en los ejemplos correspondientes a don Bernalt, arcediano de Pedroche ${ }^{21}$, a don Ruy Fernández, arcediano de Córdoba ${ }^{22}$, a don Sebastián, arcediano de Castro ${ }^{23}$, y a don Juan Martín de Tapia, canónigo ${ }^{24}$.

El número de familiares y criados de los capitulares fue variado. La casa, naturalmente, fue aumentando el número de servidores a medida que el titular de la misma incrementaba su importancia social y económica, lo que solía suceder con el transcurso del tiempo y el ascenso a cargos de dignidad, si finalmente no accedía al episcopado.

Podríamos seguir ofreciendo ejemplos y datos sobre las casas particulares de cada capitular. Pero resulta más ilustrativo de cuanto queremos decir, que aludamos a dos documentos: un privilegio del rey Juan II del año 1431 y una carta de seguro del mismo rey a favor de los eclesiásticos de Córdoba y de sus servidores, de 1448.

1819 de diciembre de 1321. B.C.C.,Ms. 125, ff. 141r-142r. Deja sus casas de morada, en las que habita, a su nieto Juan (que debía ir para clérigo, pues también recibe varios libros litúrgicos de su abuelo), y tenia dos hijas y otros dos nietos.

${ }_{19}$ Eran sus hijos Ferrando y Pedro, hijo de doña María con quien vive el testamentario y criado de Gómez Garcia y Juana, y Juana hija de Lucia, vivía también con su hermana doña Olalla y además tenía hermanas doña Maria y doña Moñina. Testamento de 8 de marzo de 1316. B.C.C., Ms. 125, ff. 136-137.

20 Deja a sus hijos habidos de doña Catalina, su mujer, Teresa, Mayor, Martín, Pedro, Juana y Catalina sus casas principales y los mayores bienes raices. También hace mandas a varios sobrinos. Testamento de 10 de marzo de 1301. B.C.C., Ms. 125, ff. 135-136.

21 En su testamento de 15 de noviembre de 1294 se citan los criados siguientes: Lorenzo Martinez, doña Sancha mujer que fue de Pedro Martinez el almocadén, Juan Fernández, Teresa, Ferrando marido de doña Teresa, Alfonso, Ferrand González, Domingo, don Per Yváñez, Garci Alfonso clérigo de Cabra, Domingo Pérez sacristán en la catedral, doña Katerina mujer de su criado Alfonso Pérez, Sancho Gil. B.C.C., Ms. 125, ff. 128-129.

22 Cita entre sus criados al collazo que fue de Valdecañas de Yuso, su ama doña Urraca, Alfonso, Rodrigo Remírez, Domingo Juan, Pero Garcia clérigo de San Lorenzo. B.C.C., Ms. 125, ff 142-144.

23 Aparecen citados los criados Domingo Pérez, Mari Gómez, Diago, Gonzalvo, Diaguillo, los siervos Juan Alfonso y su mujer Mari Ferrández reciben 50 mrs. y «que sean forros, libres e quitos depués de mis dias et mándoles más la mi casa que yo he... y Ferrand Pérez. Testamento de 12 de mayo de 1282. B.C.C., Ms. 125, ff. 137-138.

24 Aparecen citados sus allegados y criados, sin que aludamos a sus familiares, su comadre Elvira Garcia, doña Sol (que vive en casa del canónigo), las hijas de doña Mayor (que provienen de la tierra del canónigo), García Martínez criado hijo de don Thomás de Segura, Elvira (sobrina y criada), Sancha (que vive en casa del canónigo), Fátima su sirvienta (que es "forra» desde hace tiempo y sigue a su servicio), cuenta con hombres a sueldo («...que fagan cuenta con mis omes assoldados e que les den todo lo que alcançaren que an de aver») y criados son también Pero García, Bartolomé Martínez y Juan. Testamento de 8 de marzo de 1304. B.C.C., Ms. 125, ff. 131-133. 
El primer documento es la concesión de excusar de ir a la guerra de Granada a los oficiales y servidores del cabildo: un pertiguero, un organista, un campanero y un escribano y gran número de otros sirvientes del cabildo hasta un total de 40 , "ca mi merced e voluntad es que los dichos vuestros oficiales e continos comensales servidores fasta el dicho número non se comprendan so los dichos pregones fechos e por fazer» de ir a la guerra ${ }^{25}$.

El segundo documento es una carta de seguro, que consta en una serie de privilegios y mandamientos reales y que fue pregonada por la ciudad de Córdoba el día 3 de marzo, domingo por la tarde, y el día 4 de marzo de 1448. En la carta de seguro aparecen los nombres de los clérigos de la catedral, especialmente de los miembros del cabildo catedralicio, más los nombres de los clérigos de las parroquias de la ciudad de Córdoba y, finalmente, los siervos de los capitulares, que también son beneficiarios de la carta de seguro, y que son los que ofrecemos en nota ${ }^{26}$.

Las tareas de los miembros de las casas de los capitulares cordobeses podían ser varias ${ }^{27}$. Pero, en cualquier caso, fueron solidarios en muchas de las obliga-

2520 de junio de 1431. A.C.C., caj. N, n. 173. R.A.H., 9/5436, ff. 341-342.

25 «Diego Ruis e Juan Romero e Pero Martínez e Pero Dias notarios. E Juan Ruis notario e Luis Fernández notario. Pero Álvares e Manuel Quesada alguasiles. Juan Rodrígues e Vasco Gómes porteros del obispo... Familiares e criados de los dichos sennores deán e cabildo e sus personas de suso nombradas son los que ay dirá en esta guisa. Familiares del dicho deán: Pero Lópes clérigo, Sancho Gonçáles de Sepúlvega, Juan de Gómara, Pedro de Aguirre, Pedro Francés, Diego de Trujillo, Miguel de Alcalá. Familiares del arçediano de la ciudad: Bartolomé Sánches Serrano, Pero Ruis de la Fuente Santa, Pero Ferrándes de Santa Olalla, Pero de Montemayor, Pero Serrano, Juan Rodrígues de Palencia. Los familiares del chantre: Alfón Martínez de Ribera e Lope Garçia de Córdova, Juan de Aguayo, Juan de Castro, Sancho de Gama, Juan de Gama, Gonçalo Munnos, Gil de Soria, Alfón Ferrándes del Canto. Los familiares del dicho arçediano de Castro: Gonçalo de Montoya, Alfón de Padilla, Rodrigo de Jahén, Pero Gonçáles de Góngora, Diego de Góngora. Los familiares del dicho maestrescuela: Antón Sánches de Valladolid, Alfón de Trillo, Pero Martínes de Lerma, Juan Martínes, Lope Ferrándes, Juan de Córdoba. Los familiares del dicho thesorero: Diego Garçía, Rui Garçía, Antón, Juan de Córdova tijo de Juan Gonçáles, Ferrando de la Vereda. Los familires del dicho prior: Juan de Alcalá, Diego García, Diego de Córdova, Altón de Jaén. Los familiares del dicho Pero Martines de Salinas: Juan de Montilla, Juan Rodrigues de Useda, Ferrando de Salinas, Juan de Salinas. Los familiares del dicho Gonçalo de Rojas: Pedro de Fonseca, Ferrando de Carrión, Altón, Juan Péres, Juan de Palençia. De Alfón Martínes doctor: Françisco Gonçáles, Pedro de Sevilla. Los familiares del dicho Antón Ximénes: Alfón e Françisco. Los familiares del dicho Pero Martines bachiller: Pedro de la Cueva, Nicolás su sobrino, Gonçalo de Alcalá, Juan Sillero, Juan Gonçáles, Pedro de Córdova. Los familiares del dicho Juan Martines: Garçía, Rodrigo de Córdova, Juan de Carmona, Alfón de Córdova, Lope de Bermeo. Los familiares del dicho Juan Sánches: Juan de Ayllón, Miguell de Ayllón. Los familiares del dicho Alfón Gonçáles: Ortunno, Ferrando. Los familiares del dicho Antón Garçia: Miguel Ximénes e Juan Garçia. Los familiares de Martín Altón: Diego Alfón, Pero Ruis corredor, Benito. Los familiares del dicho Diego Álvares: Alfón Caro, Lásaro. Los familiares del dicho Diego Sánches: Lope de Jaén, Gonçalo Garrovillo, Juan Daguero, Estevan. Los familiares del dicho Alfón Díaz de Vargas: Diego Días, Ferrando, Juan Sánches. Los familiares del dicho Bartolomé Sánches: Antón Sánches clérigo, Alfón Lópes, Juan. Los familiares del dicho Ferrán Sánches: Ferrando, Françisco, Juan. Los familiares del dicho Martín Ferrándes: Ferrando Calderón, Diego, Gonçalo. Los familiares del dicho Alfón Martínes compannero: Juan Gonçáles. Los familiares del dicho Ruy Dias: Rodrigo e Juan e Lope. Los familiares del dicho Gonçalo Garçía: Miguel Sánches e Benito. Los familiares del dicho Juan Garçia de Henares: Ferrand Arias, Juan, Diego. Los familiares del dicho Gonçalo Gutiérrez: Ferrando, Juan, Goncalo de Fornachuelos, Juan Martines, Johannes Garçie". Córdoba 2-3 y 4 de marzo de 1448. A.C.C., caj. P. n 39.

27 Incluso podían llegar a realizar funciones de "matones", que se recriminan en una ordenación capitular de 1434, donde se denuncia que aigunos capitulares habian sufrido amenazas e injurias por parte de los parientes de cierto beneficiado, que habia sido justamente castigado por el cabildo catedralicio. 
ciones y en muchos de los privilegios de estos capitulares, como hemos podido entrever hasta ahora. Esta solidaridad se comprueba también en la participación que los familiares, clientes y criados de los capitulares tienen en los arrendamientos y subarrendamientos de bienes raíces del cabildo catedralicio. Desde la primera copia completa de una cesión en arrendamiento de una aranzada de tierra calva a favor de Martín Jiménez, criado del canónigo Juan Rodríguez, en 1296, hasta las últimas fechas de arrendamientos que hemos estudiado hasta mediados del siglo Xv, comprobamos la existencia de al menos 45 arrendamientos de bienes raíces capitulares en manos de criados o servidores de los miembros del cabildo. Esto a pesar de que lo usual era que el arrendamiento nominal y el pago de la renta se apuntara al capitular y el bien se traspasara sin documentación a su criado. Los bienes arrendados solían ser principalmente casas en la collación de la catedral ${ }^{28}$.

Finalmente, sólo queremos señalar que el obispo y los capitulares mantenían un lugar determinado en la catedral, denominado "nave de los criados", destinado al entierro de los criados de los capitulares, cuya fosa se dotaba por estos últimos en cumplimiento de su deber de cabezas de su casa ${ }^{29}$.

\subsection{La casa de los obispos}

Después de dar un somero repaso a varios de los datos que poseemos sobre la casa de los clérigos de entre los cuales se solía elegir a los obispos y que, como se ha visto, podian cumplir también con el requisito paulino de gobernar bien su casa, pasamos a observar la casa de los obispos de Córdoba.

Por desgracia, poseemos pocos datos sobre este asunto referidos a los obispos, pues la documentación que pudo existir en el palacio episcopal de Córdoba fue objeto del fuego y de sustracciones varias. Por lo cual manejamos una documentación muy similar a la ya vista anteriormente, más indiciaria que descriptiva y siempre insuficiente. Pero creemos que, como dijimos al comienzo, el esfuerzo puede merecer la pena, abriendo caminos a otros investigadores y a las posibilidades que ofrezca la documentación en otros lugares.

2.2.1. El palacio episcopal.-El palacio episcopal de Córdoba se denominó generalmente a lo largo de la E. Media como «la casa del obispo" y se ubicó en el mismo lugar que ahora ocupa el palacio episcopal junto a la catedral cordobesa, si bien no poseemos ninguna descripción arquitectónica de la misma.

Teniendo presente el cabildo que no era la primera vez que sucedia, se pena en adelante tal conducta condenando al capitular que utilizó asi a sus parientes para amedrentar a los demás compañeros, a una multa de $2.000 \mathrm{mrs}$. y a un año de ausencia de la catedral, donde no pueda ganar la parte de su beneficio condicionada a las presencias personales. 31 de marzo de 1434. B.C.C., Ms. 166, f. 76.

2817 de diciembre de 1296. B.C.C., Ms. 125, f. 105. Consúltese I. SANz SANCHO, La Iglesia y el Obispado de Córdoba en la Baja Edad Media (1236-1426), 2 vols., Madrid, 1989, "Apéndice II: Cuadros de arrendamientos de propiedades del cabildo catedralicio hasta 1445". II, pp. 1376-1462.

295 y 7 de diciembre de 1446. A.C.C., caj. L, 135. 
A la casa episcopal, tanto en el sentido del edificio, como en el de grupo humano y organismo rector en manos del obispo, se refieren preferentemente varios pasajes significativos, que entresacamos de la documentación.

El obispo don Pascual se ve obligado a aclarar ante el cabildo catedralicio el uso no reglamentario que hizo de sus casas episcopales en 1288, escudándose en su enfermedad: «Sepan quantos esta carta vieren cómmo nos don Pascual, por la gracia de Dios obispo de Córdova, otorgamos a vos el deán e cabildo de nuestra eglesia que, porque vos viniestes a nuestra casa a dar la canongía que fue de Domingo Ramiro, por razón que nos estávamos doliente, que non sea preiuyzio del cabildo de aquí delante de dar los beneficios en nuestra casa. Et porque esto non venga en dubda, mandamos vos dar esta carta abierta seellada con nuestro seello pendiente. Dada en Córdova, primero día de agosto, era de mill e trezientos e veynte e seys annos. Iuan Alfonso" ${ }^{30}$.

El deán del cabildo catedralicio defiende el fuero, pues se debía colar la canongía por ambas instancias, obispo y cabildo catedralicio, en la catedral y no en la casa episcopal. En consecuencia, el obispo bien podía haber enviado a su representante ante el cabildo, como hará en la mayor parte de las sesiones capitulares.

Un caso similar se repite al menos otra vez en el episcopado de don Fernando González Deza, cuando varios miembros del cabildo catedralicio protestan formalmente ante este obispo, porque hizo que el cabildo acudiera, mediante llamamiento del pertiguero episcopal, a la casa del obispo para tratar sobre ciertas permutas, asunto que sólo debía hacerse en la sala de reunión capitular ${ }^{31}$.

El asunto no era baladí, puesto que, aunque el consistorio del obispo también se hallaba en la catedral, sin embargo, su casa y su curia episcopal dependían en gran medida de su gobierno personal y, en consecuencia, bien podía trasladar a sus casas episcopales estos servicios, creando las estancias necesarias para su desarrollo y liberando a la catedral de esta servidumbre. Era cuestión de tiempo y de medios económicos y personales.

En 20 de abril y en 11 de mayo de 1479 el concejo de la ciudad de Córdoba se reunió en la huerta de las casas del obispo, para tratar, respectivamente, de la prohibición de alojar a judíos y moros en casas de cristianos de la ciudad y de la contribución del concejo en los juegos del día del Corpus Christi de este año ${ }^{32}$.

Pocos años antes las casas del obispo de Córdoba habían sufrido graves perjuicios, con asaltos armados e incendios que mandó realizar don Alonso de Aguilar en tiempos del obispo don Pedro de Córdoba y Solier (1464-1476), quien,

30 B.C.C., Ms. 125, f. 38 . Ms. 166, f. 14. R.A.H., Ms. 9/5.430, f. 45.

31 Córdoba, 3 de febrero de 1424. Los miembros del cabildo que elevan la protesta formal fueron Lope Gutiérrez de los Ríos bachiller en decretos y maestrescuela, Fernando Ruiz de Aguayo chantre, Juan Rodríguez tesorero, Alfonso Fernández prior, Antón Gómez canónigo, Martín Jiménez canónigo y Pedro Martínez de Salinas bachiller en decretos y canónigo. A.C.C., caj. M, n. 69.

32 Archivo Municipal de Córdoba (en adelante A.M.C.), Actas capitulares, año 1479. 
además, fue expulsado de la ciudad y hubo de vagar por sus otras casas episcopales y señoriales, propias y de nobles cordobeses partidarios suyos ${ }^{33}$. Por lo cual no es extraño que todavía en el episcopado de don Íñigo Manrique de Lara (14851496) aparezcan varias constituciones sinodales, estableciendo que la mitad de ciertas multas pecuniarias se dediquen a las reparaciones de la casa episcopal y no sólo para la cámara episcopal o la obra de la catedral ${ }^{34}$.

Pueden ser tenidas también por "casa del obispo", incluso en el sentido de edificio habitable, una serie de construcciones en las que los obispos cordobeses pasaron ciertas temporadas, bien a causa del recreo y del descanso, a causa de una mejor administración de las propiedades y señoríos episcopales o, incluso, a causa del refugio que hubieron de tomar al ser perseguidos y aún expulsados de la ciudad de Córdoba.

Podemos señalar varios lugares de residencia, que sin duda utilizaron los obispos de Córdoba durante algún tiempo. En primer lugar, las residencias y construcciones principales de los señoríos episcopales poseídos hasta el año 1342, que se habian ido perdiendo paulatinamente desde finales del siglo xill: señorío de Lucena, villa y castillo de Bella y castillo Anzur. En segundo lugar, las edificaciones de los nuevos señoríos episcopales del castillo de Toledillo (que contuvo también la cárcel episcopal) y del castillo de Aznaviada. Finalmente, las edificaciones propias, patrimoniales, de los obispos en sus propios señoríos, como los de Zuheros y el Fontanar (propios del obispo don Pedro de Córdoba, con los que heredó respectivamente a sus dos hijos naturales varones) o las casas del obispo don Sancho de Rojas (1440-1454) en Baena, señorío de su hermano paterno, el mariscal don Diego Fernández de Córdoba, señor de Baena y de Cabra (donde pasó algunas temporadas, ordenando de diácono al deán don Fernando Pérez de Contreras en las témporas del Adviento del año 1444) ${ }^{35}$.

2.2.2. Los componentes de la casa del obispo.-La casa de los obispos de Córdoba se componía de familiares, clientes, escuderos, criados y sirvientes, clérigos y capellanes, notarios y escribanos, principalmente. Además, hay que tener en cuenta que algunos de estos miembros podían formar parte de la curia episcopal y también que otros cargos de confianza y de representación de la persona y de los intereses episcopales podían integrarse temporalmente en la casa del obispo.

Conocemos pocos testamentos otorgados por los obispos cordobeses, aunque hay copia de cláusulas relativas a sus donaciones pro anima, pero que no suelen contener información sobre nuestro tema.

33 Un resumen de este y otros sucesos del episcopado de don Pedro de Córdoba puede verse en I. SANZ, «Los obispos del siglo Xv", op. cit., pp. 635-660.

34 "yncurra en pena de mill mrs., la mitad para la fábrica de la nuestra yglesia e la otra mitad para los reparos de nuestra casa obispal». Museo Británico de Londres. Additions 10.237, f. 31.

35 Para mayor información sobre los señoríos episcopales, remitimos al lector a nuestro trabajo, 1 . SANZ SANCHO, "El poder episcopal en Córdoba en la Baja Edad Media", en En la España Medieval, 13 (1990), 163-205. Para los otros asuntos dichos, véase IDEM, "Los obispos del siglo XV», op. cit. 
El primer ejemplo es el testamento de don Fernando obispo de Calahorra, que antes había sido maestrescuela y arcediano de Córdoba, por lo cual puede ser representantivo del tipo común de obispo cordobés a comienzos del siglo XIV. Entre sus criados aparecen citados Gutier Pérez, Domingo Royz, el collazo Pero Pérez el Negro, el camarero Fernand González, Miguel Sánchez, Diago y Pero Johan ${ }^{36}$.

Otro testamento episcopal es el de Fray Gonzalo de Illescas, monje jerónimo, de mediados del siglo xv. Sabemos que obtuvo del papa en 1455 la gracia de poder tener consigo a dos frailes jerónimos del monasterio de Guadalupe y por su testamento observamos que su casa estaba compuesta por confesor, capellán, secretario, contador, limosnero, cahicero (receptor del pan), y mayordomo para la percepción de las rentas y la administración de la mitra, escuderos de a pie y de a caballo, mozos de espuelas, etc., mientras que sus "familiares" proceden generalmente de Guadalupe, de Illescas y de algunos pueblos toledanos.

Lógicamente, se rodeó también de naturales cordobeses, aunque no formaran parte directa de su casa, que le ayudaron en los asuntos más propiamente curiales y pastorales. Entre sus colaboradores pueden citarse a su provisor y procurador en bastantes ocasiones Alvar González de Capillas, a su capellán Fernando Sánchez de Trujillo, a sus albaceas testamentarios el chantre Fernando Ruiz de Aguayo y el compañero Diego Fernández y a su vicario general Martín Alfonso de Córdoba ${ }^{37}$.

36 2 de julio de 1303. Codicilo de 5 de mayo de 1303. B.C.C., Ms. 125, ff. 130-131.

37 Testamento de Hornachuelos, 8 de octubre de 1464. El obispo manda que sus familiares y criados le lleven a enterrar a su sepultura labrada con busto de alabastro del monasterio de Guadalupe, con una serie de requisitos de responsos y ceremonias religiosas a cumplir durante el trayecto: "que luego sea tenudo por nuestros criados e familiares, a los quales mandamos e otorgamos que en los lugares donde ovieren de reposar a comer o a dormir, pongan el dicho nuestro cuerpo en las eglesias de los dichos lugares, en entrando por la eglesia digan un responso..., nuestros capellanes digan una misa de requiem rezada o cantada...", etc.

Además, les hace las siguientes mandas: "ltem mandamos a todos nuestros criados e familiares que se fallaren al tiempo de nuestro finamiento que con nos biven, por cada un anno de quantos cada uno dellos oviere con nos bevido, conviene a saber, a los escuderos milie maravedis por cada hun anno a cada uno dellos, e a los ommes de pie e al nuestro moço de las espuelas e a los moços de nuestra cámara a cada uno dellos por cada huno anno quinientos maravedis del tiempo que con nos ovieren bevido. $E$ esto se entienda que se den e paguen a los que de nos non ovieren avido ayuda de casamiento, porque aquellos a quien ayudamos para sus casamientos fueron de nos satisfechos en lo que les dimos. Empero, plázenos que a los que fueren fallados que después que fueron casados continuaron en nuestro serviçio e fueron continuos comensales e non bivieron por tierra, que les sea dado a cada uno dellos por cada un anno mille maravedis, desde que fueron casados en adelante. $E$ assimesmo queremos que sea dado a cada uno de los escuderos que nos encavalgamos, desde el día que fueron encavalgados e continuaron con nos fasta el dia de nuestro finamiento, que les sea dado por cada hun anno mille maravedis. Item mandamos que a los capellanes que fueren fallados que non ovieron benefiçio alguno en el tiempo que en nuestra compannia estovieron, que assimesmo les sea dado cada mille maravedis por cada un anno, e esto se entienda de los que fueron continuos comensales".

Además, aparecen citados Juan Ruiz de Guadalupe su mayordomo, que se encarga de recibir y cobrar los frutos y rentas de la mesa episcopal, pues tiene poder escrito para ello. Pedro de Yllescas su cahicero, que por su especial mandato también se encarga de recibir el pan de la mesa episcopal que está en los alfolies episcopales. Fray Juan de lliescas, profeso del monasterio de Guadalupe, su limosnero. Juan Romero, escribano público, su contador.

Pueden verse otros datos sobre este obispo en I. SANZ, “Los obispos del siglo XV», op. cit, pp. 625635. 
Como ha podido advertirse, la casa del obispo era amplia, incluso en el caso de un obispo que era monje jerónimo. Pero, todavía hay que añadir otros cargos y clientes encargados de bienes y asuntos hasta ahora no tratados, como pueden ser los curiales y los caballeros y laicos que se encargaron de la defensa armada de las propiedades y castillos episcopales, los alcaldes que se encargaron de administrar justicia en los señoríos episcopales, los alguaciles, el pertiguero, el portero, los carceleros, etc. Por desgracia, desconocemos la mayoría de estos datos, algunos de los cuales aparecen dispersos por la documentación, por más que debemos suponerlos.

Así, en 1263 el rey Alfonso X apoya el derecho de la Iglesia de Córdoba a designar sus propios alcaldes en las aldeas de sus señorios y conocemos a don Remiro, alcalde de Lucena, ese mismo año ${ }^{36}$. El componente militar de la casa de los obispos debió rebajarse drásticamente después de 1342, cuando los señorios episcopales se redujeron a poco más de dos fortalezas, si bien en los episcopados de don Sancho de Rojas y de don Pedro de Córdoba y Solier, a causa de las banderías y enfrentamientos nobiliarios, aparecerían más alcaides de castillos y hasta de la casa episcopal y de la catedral, que hubieron de encastillarse ${ }^{39}$.

Por lo demás, alguaciles, carceleros, pertigueros y cocineros, además de clérigos, secretarios y escribanos o notarios del obispo, criados, etc. aparecen también como arrendadores de algunos bienes raíces del cabildo catedralicio ${ }^{40}$.

\subsection{La casa y la curia episcopal}

Si para la Edad Media la diferenciación neta entre la Casa y la Corte de los reyes resulta no sólo difícil, sino también desaconsejable, aún más lo es para los dos órganos consuetudinarios de la administración episcopal, la casa, más próxima a la administración de lo privativo del obispo (mesa, señoríos, familiares y necesidades propias) y la curia, órgano administrativo más próximo a la acción pública de la administración pastoral y jurisdiccional del obispo (cancillería, cámara, consistorio).

Ambos órganos dependian de la voluntad episcopal, resultando dúctiles a la hora de dar soluciones inmediatas a problemas nuevos y concretos, sin tener que contar con la cooperación de otras instancias. Ahora bien, si los oficios y los cargos de la casa eran de inmediata dependencia del obispo, porque era quien directamente los pagaba de sus rentas, los oficios y los cargos de la curia, que la mayoría de las veces estaban dotados con beneficios clericales instituidos o bien eran pagados con las entradas de los aranceles de cancillería o de cámara, tenían

${ }^{38}$ Sevilla, 1 de abril de 1263. A.C.C., caj. P, n. 51. Aguilar, 18 de diciembre de 1263. B.C.C., Ms. 125, ff. 46 y 73

${ }^{39}$ En sede vacante, el cabildo catedralicio debia designar, entre otros oficiales, a los aicaides del castillo de Toledillo, de la Alameda del Obispo, de las casas episcopales de Córdoba y de la catedral. B. FRESNEDA, Estatutos, op. cit., p. 70.

40 Véase nota 24. 
una dependencia más mediata del obispo, quien debía contar con personas bien formadas en los dos derechos, canónico y civil, y en otras disciplinas eclesiásticas y administrativas.

En consecuencia, la curia episcopal solía componerse en ciertos cargos especializados, particularmente de jueces y de actividades administrativas y pastorales mayores, de personal procedente del cabildo catedralicio, reservándose otros cargos más comunes y menos especializados, como el de escribanos y notarios, a clérigos no capitulares. Pero esto no quiere decir que el obispo no procurara y muchas veces consiguiera que la mayoría de estos altos cargos fueran desempeñados por gente de su casa en un sentido estricto y sobre todo en un sentido más amplio de clientela y amistad. Consecuentemente, la curia episcopal dependía en gran medida también del obispo, a través de los miembros de su casa $^{41}$. No hay que olvidar que el obispo era la cabeza, fuente y origen de la Iglesia local en lo sacramental, doctrinal, jurisdiccional y administrativo-pastoral, aun cuando ciertas disposiciones canónicas delimitaran algunas formas y campos de actuación $^{42}$.

La curia episcopal se fue desarrollando, como paralelamente la casa, a medida de las necesidades de una administración y una pastoral cada vez más burocratizadas y con un encauzamiento mínimo por parte de las disposiciones canónicas y papales. Al final de su desarrollo en la Edad Media, la composición de la curia episcopal, según el sínodo diocesano de 1520, sería como sigue:

Gira fundamentalmente sobre lo que se denomina el «consistorio» y también la "audiencia" del obispo, que es el lugar de la catedral donde tienen audiencia el provisor, los vicarios, los jueces ordinarios y los delegados y los oficiales episcopales e imparten la justicia episcopal a diario en las horas acostumbradas de la

41 A conclusiones parecidas llega R. A. FLETCHER, The episcopate in the Kingdom of Leon in the twelfth century, Oxford, 1978, cap. III. No obstante, el autor se ciñe demasiado, a nuestro entender, a un sentido que él llama "estricto" de la "casa" episcopal, por lo que afirma que en puridad, dejando aparte el asunto de los componente laicos de la casa: familiares y caballeros, no existió la casa episcopal en los obispados del Reino de León en el siglo XII, pues estaba mezclada con los clérigos del cabildo catedralicio. Es decir, la casa episcopal consistiria únicamente en los que vivian de las rentas episcopales en exclusiva y no de otras prebendas eclesiásticas. Por lo cual admite que, junto con los capitulares, los obispos tuvieron otros colaboradores no capitulares, como secretarios y capellanes domésticos, pero que no llegaron nunca a formar una verdadera casa episcopal.

42 A una mente actual puede resultarle extraño esta forma de organización administrativa, con tan alta dependencia de un teórico personalismo episcopal. Sin embargo, incluso en la actualidad, en la doctrina católica, el obispo y su oficio episcopal es la fuente y cabeza única en todo de la Iglesia local.

Esta situación tiene cierto paralelismo con el análisis que el profesor Ladero hace de la evolución de los medios de gobierno, Casa y Corte, en la Baja Edad Media y en la monarquía de los Reyes Católicos: «La Casa del rey y sus oficios fueron en Castilla el núcleo principal de organización y acción administrativa, de modo que el poder real legitimaba directamente a toda ella. Es anacrónico contraponer oficios "domésticos" y oficios "públicos", así como Casa y Corte, aunque de hecho fueron diferenciándose las dos esferas ... Más importante es distinguir entre actos administrativos despachados por expediente, de acuerdo con procedimientos habituales y, en general, reglamentados, y asuntos despachados por cámara, según merced y gracia regias. En aquel ambiente, crece la importancia política de los secretarios reales, que en principio son oficios domésticos...". M. Á. LADERo QuESADA, La España de los Reyes Católicos, Madrid, 1999, pp. 242-243. 
mañana. Dicha justicia es gratuita, con las advertencias debidas de si aparecen letrados y circunstancias distintas de las habituales, que han de pagar las partes interesadas ${ }^{43}$.

Son también parte de la curia el promotor fiscal, el vicario general y cualesquier otros vicarios específicos, los letrados, los notarios de la audiencia y de las rentas decimales, los escribanos, el secretario. Como ayudantes y ejecutores de los jueces episcopales están también el alguacil, el portero y los carceleros, cuyas tasas por intervenciones quedan fijadas en la tabla de aranceles, junto con las de los notarios y escribanos, en el sínodo diocesano de 1520, que recoge en gran medida la tabla anterior del obispo don Íñigo Manrique (1485-1496) y que, a su vez, es una de tantas actualizaciones de aranceles de obispos anteriores.

\subsection{Conclusión: importancia de la casa del obispo}

La importancia de la casa del obispo dentro del orden teórico-práctico del gobierno episcopal de la diócesis y del señorío que detenta, es decir dentro de las normas reguladoras del derecho canónico y de los usos políticos, es determinante, puesto que es el órgano de gobierno más inmediato a su persona, que informa a los demás órganos y medios de gobierno en manos del mismo obispo. Todo esto en el contexto de una Iglesia donde domina el episcopado monárquico y en una sociedad en la que la cooperación de los obispos en la administración del Estado fue también decisiva.

Hemos visto en el testamento de Fray Gonzalo de Illescas cómo el obispo tiene una serie de obligaciones con los miembros seglares, casados y solteros, hombres y mujeres, y con los miembros clericales de su casa. Sobre estos últimos decía: «item mandamos que a los capellanes que fueren fallados que non ovieron benefiçio alguno en el tiempo que en nuestra compannia estovieron, que assimesmo !es sea dado cada mille maravedis por cada un anno, e esto se entienda de los que fueron continuos comensales".

Es decir, que tanto los clérigos familiares como los clérigos criados del obispo esperaban ser colocados en algún cargo de confianza episcopal y que gozaran de un beneficio clerical congruo. Recuérdese al respecto que la mayoría de los beneficios eclesiásticos eran de colación episcopal y que otros, como los del cabildo catedralicio, eran de colación conjunta (in solidum) del obispo y del cabildo, por to

43 «Por quanto las rentas y patrimonio que nuestra yglesia tiene son deputadas para soportar los cargos de nuestra dignidad pontifical. E porque nos mesmo no podriamos oyr todas las causas y pleytos, que vienen a nuestra audiencia y pertenecen a nuestro juizio eclesiastico, somos obligado de derecho tener oficial general, que las oya y se asiente en el nuestro consistorio para las juzgar. Al qual nos tenemos de proveer y sostener en sus necesidades. E podria ser, que el tal provisor o oficial llevasse por la vista de los procesos accesorias de las partes, que ante ellos litigan. Sancta synodo approbante, ordenamos y mandamos, que por lo tal no se lleve cosa alguna de las partes ni de alguna dellas". A. MANRIQUE, Constituciones Sinodales del Obispado de Córdoba, Sevilla, 1521, Título III. "Título tercero. De las cosas que se han de guardar en nuestro consistorio". 
que el obispo podía disponer de una parte de los beneficios vacantes o, como veremos, crear otros nuevos cuando lo estimara necesario.

Así, desde el principio de la restauración de la Iglesia de Córdoba anotamos la presencia de familiares y servidores o criados del obispo en beneficios clericales, desde miembros del cabildo catedralicio hasta beneficiados de iglesias rurales. Los ejemplos son muchos y variados, de los que entresacamos los de don Martín de Fitero, sobrino del primer obispo de Córdoba, don Lope de Fitero ${ }^{44}$; Alfonso Fernández, camarero del obispo don Alfonso de Vargas ${ }^{45}$; el chantre Fernando Ruiz de Aguayo y sus hermanos los canónigos Pedro Ruiz de Aguayo y Pedro Díaz de Aguayo, que también será arcediano de Castro, sobrinos del obispo don Fernando González Deza ${ }^{46}$; García Pérez, sobrino del obispo don Andrés ${ }^{47}$; el obispo don Gutierre Ruiz de Mesa, sobrino del obispo don Fernando de Mesa ${ }^{48}$; Lope Martínez sobrino del obispo don Fernando Gutiérrez ${ }^{49}$; Martín Pérez, capellán del obispo don Fernando Gutiérrez ${ }^{50}$; Mateos ${ }^{51}$; Pedro Alfonso, sobrino del obispo don Alfonso de Vargas ${ }^{52}$; Ruy Fernández de Mesa, sobrino del obispo don Fernando de Mesa ${ }^{53}$. Como ejemplos últimos podemos poner al capellán del obispo don íñigo Manrique, Juan del Castillo, y al secretario del mismo obispo, Juan de Falces, a quienes dicho obispo dotó respectivamente con los beneficios rurales creados por el mismo obispo poco antes en Belmonte y en Valenzuela ${ }^{54}$.

La relación clientelar de varios miembros del cabildo catedralicio y del clero urbano con el obispo es perceptible en los documentos, aunque la demostración no es fácil. Pero es evidente que elegiria como cooperadores bien instruidos a los capitulares y a los clérigos con los que mantuviera una relación de confianza, de amistad y próxima a la relación clientelar, cuando menos, que beneficiaba a ambas partes. En consecuencia, era esta otra vía importante de penetración de la casa episcopal en los medios ordinarios del gobierno episcopal, que no sólo eran la casa en sentido estricto y la curia, sino también los sínodos diocesanos, las visitas

${ }^{44}$ Era canónigo de Córdoba en 1242, maestrescuela en 1244 y será arcediano de Córdoba al final de su vida. I. Sanz, La Iglesia y el Obispado, op. cit., II, “Apéndice I: Nómina de miembros del cabildo catedralicio de Córdoba de 1238 a 1430", pp. 1344-1375.

45 Compañero en el cabildo catedralicio en 1379 y en 1382. Ibidem.

46 Sobrino del obispo don Fernando González Deza, que era canónigo antes de acceder a la chantría en 1419 hasta su muerte en 1467. Ibidem. En las actas de resignación en manos del obispo, don Fernando Gozález Deza, del cargo por el anterior chantre, don Pedro Martínez de Salinas, y de aceptación por el nuevo chantre Aguayo aparecen Gonzalo González de Viedma consobrino del obispo, Rodrigo Díaz camarero del obispo y Fernando Álvarez de Morales alguacil mayor y maestresala del obispo. A.C.C., caj. N, nn. 64 y 65.

47 Arcediano de Castro en 1376 y en 1387. I. Sanz, La Iglesia y el Obispado, op. cit., II, Apéndice I, pp. 1344-1375.

48 Arcediano de Pedroche en 1300, deán en 1309. Ibidem.

49 Canónigo y varios años vicario general, como en 1322. Ibidem.

50 Capellán y compañero del cabildo catedralicio en 1321. Ibidem.

51 Clérigo del obispo don Fernando de Mesa y compañero del cabildo catedralicio en 1262 y 1277 Ibidem.

52 Racionero del cabildo catedralicio hacia 1380. Ibidem.

53 Deán en 1284. Ibidem.

54 Medina de Pomar, 28 de julio de 1496. A.C.C., caj. I, n. 357 
pastorales, los estatutos y mandatos episcopales, los órganos de gestión de las rentas decimales, que también tenían representantes episcopales, etc.

Pero la casa episcopal no sólo fue el elemento dinamizador y el medio más dúctil del gobierno episcopal, que se hallaba presente de una forma u otra en los demás órganos de gobierno e instituciones diocesanas, sino que también demostró ser el medio indispensable y capaz de sustituir a los demás medios en momentos tan dramáticos para el gobierno episcopal como fueron los últimos años del episcopado de don Sancho de Rojas (1440-1454) y todos los años del episcopado de don Pedro de Córdoba y Solier (1464-1476) ${ }^{55}$.

Ciñéndonos al caso del obispo don Pedro, debemos recordar que casi todo su episcopado se desarrolló fuera de la ciudad y de su palacio episcopal de Córdoba, por la expulsión violenta que experimentó al principio de parte de don Alonso de Aguilar y de sus partidarios y por las persecuciones que en la ciudad y en los señoríos del mismo don Alonso y de sus parciales sufrió durante el resto de su episcopado en el territorio rural de la diócesis.

Nuestro obispo no sólo se vio desasistido de muchos medios materiales, que se encontraban en la ciudad y en los señoríos de don Alonso y de sus seguidores, sino también de las tradiciones, los hábitos y los usos que centralizaban en la misma ciudad la gestión episcopal. Peor aún será que don Alonso consiguiera enfrentar a la mayor parte del cabildo catedralicio contra su obispo y que las causas surgidas entre ambos llegaran a Roma, con acusaciones y reproches graves de todo tipo. Por su parte, la Universidad de Clérigos Beneficiados de la ciudad de Córdoba rehusó tomar partido y permaneció a la espera, colocada entre la espada y la pared. Esta crisis afectaba a todos los órdenes: eclesiástico (pastoral, sacramental, administrativo, judicial, etc.), económico (rentas episcopales y decimales en general) y político (enfrentamientos de bandos nobiliarios y guerra civil).

Sin embargo, esta situación de gravedad extrema en lo eclesiástico pudo ser superada gracias a la casa del obispo. En efecto, si el obispo era la cabeza, la fuente y el origen de la Iglesia local, su casa entonces actuaba como su órgano de gobierno más inmediato y fiable, mostrando claramente la voluntad del obispo. Así, sobre la base firme de su casa (en sentido lato) y los medios que aún le quedaban, el obispo reprodujo unos órganos de gobierno y de administración diocesanos allá donde fue necesario y mantuvo la conexión imprescindible con los demás órganos, que seguían funcionando razonablemente ${ }^{56}$.

55 Para la historia concreta de estos dos episcopados remitimos a I. SANZ, "Los obispos del siglo XV", op. cit., pp. 615-625 y 635-655.

${ }^{56}$ Entre los más inmediatos colaboradores eclesiásticos del obispo don Pedro hemos de citar, al menos, a don Álvaro González de Cabreros (bachiller en decretos, canónigo y familiar del obispo), don Jimeno López de Valenzuela (canónigo, oficial, provisor y vicario general), fray Antón de la Finojosa (prior del monasterio de San Jerónimo de Valparaíso), Martin Alfón de Córdoba (bachiller en decretos, vicario y juez comisario episcopal), Fernando Romero (vicario del obispo y bachiller), don Martín Fernández (chantre y vicario general), Diego Sánchez (canónigo), a los racioneros de la catedral Dien Rodríguez y Juan de Lucena, a los criados del obispo el doctor Fernando de Medina, el bachiller Pedro de Jaén, el 
Esto hizo que, a pesar de que la parcialidad del obispo fue menor en la ciudad, en el obispado y en el número de mantenedores, la posición de don Pedro se constituyó en la única posición viable, puesto que el papa no destituyó al obispo, frente a las pretensiones de don Alonso de Aguilar, quien, primero, exigió la anulación de la elección episcopal y después promovió, también sin éxito, la causa de la destitución ante la curia papal ${ }^{57}$.

bachiller Fernando de Oliva, Diego de Montoya, Lope de Porras y Juan de Padilla, al mayordomo episcopal Juan de Córdoba y al secretario del obispo Juan García, notario y beneficiado en las iglesias de San Andrés y de la Magdalena de Córdoba.

57 La crisis finalmente se cerró con la reconciliación y la anulación, en su refugio de Baena y poco antes de su muerte, de las actuaciones judiciales que habia efectuado el obispo don Pedro contra el cabildo catedralicio y contra don Alonso de Aguilar y sus parciales. En lo cual podemos ver el deseo de morir en paz que tenía el obispo después de un gobierno tan desventurado como el que le tocó vivir. 